\title{
DIODE LASER SURFACE ALLOYING OF ARMOR STEEL WITH TUNGSTEN CARBIDE
}

\begin{abstract}
Metal matrix composite (MMC) surface layers reinforced by WC were fabricated on armor steel ARMOX 500T plates via a laser surface alloying process. The microstructure of the layers was assessed by scanning electron microscopy and X-ray diffraction.

The surface layers having the WC fraction up to $71 \mathrm{vol} \%$ and an average hardness of $1300 \mathrm{HV}$ were produced. The thickness of these layers was up to $650 \mu \mathrm{m}$. The addition of a titanium powder in the molten pool increased the wettability of WC particles by the liquid metal in the molten pool increasing the WC fraction. Additionally, the presence of titanium resulted in the precipitation of the $(\mathrm{Ti}, \mathrm{W}) \mathrm{C}$ phase, which significantly reduced the fraction of W-rich complex carbides and improved a structural integrity of the layers.

Keywords: laser surface alloying, diode laser, armor steel, metal matrix composite, tungsten carbide
\end{abstract}

\section{Introduction}

Metal matrix composites (MMC) have been shown to be attractive for ballistic protection systems, especially in lightweight armoured vehicles [1-3]. Furthermore, high ballistic properties of the MMC suggest the use of such composite structures in the form of a coating on armor steel panels. It is especially reasonable to use such coatings as a strike face on substrates made of high strength quenched and tempered steels (HSQTS). HSQTS are widely used in military and civil ballistic protection systems, due to a unique combination of their properties such as high strength, hardness and ductility and also good weldability and fabricability [4-6]. Additionally, the MMC coating with metallurgical bonding to the HSQTS substrate could provide an armor system having a capability of withstanding more than a single impact, i.e. multi-hit potential. A very strong metallurgical bond between the MMC coating and the steel substrate can be achieve by using fusion coating processes [7]. However, in this case, the main issue that must be considered is the heat affected zone (HAZ) softening, leading to a deterioration of the ballistic performance of the HSQTS [8-10]. Thus, the coating technology has to provide a very low heat input needed to form the MMC coating. An additional demand for coating technology is the production of $\mathrm{MMC}$ coatings with a high volume fraction of reinforcing ceramic particles and a low degree of their dissolution in the alloy matrix [11].

Generally, laser surface treatment processes, such as the surface alloying and cladding, can meet the above-mentioned requirements [12-14]. It was additionally reported that the application of a laser with uniform intensity across the beam (a flat-top beam profile) provides the precise control of the heat input and the dissolution level of reinforcing particles during the processing of the MMC coatings [15].

The main objective of this study is to explore the possibility of the fabrication of WC-reinforced composite surface layers (SALs) on the ARMOX 500T substrate by laser surface alloying process (LSA). In order to minimize both the HAZ softening and the HAZ width, the laser used was a high power diode laser (HPDL) with the flat-top beam profile and rectangular beam spot. The influence of processing parameters on the thickness of the SAL, the volume fraction of the reinforcing particles and the extent of the HAZ was examined. Moreover, the effect of the titanium addition into the molten pool on the microstructure evolution of the alloy matrix in the SALs was established by the combination of the experimental results and the thermodynamic modelling.

\section{Experimental}

The substrate material (SM) was $10 \mathrm{~mm}$-thick Armox 500T armor steel plate with the chemical composition shown in Table 1. The microstructure of the SM consists of tempered martensite with some amount of retained austenite, Fig. 1 . The hardness of the SM was approx. $500 \mathrm{HV}$. The surface of the SM was ground to remove oxides and cleaned with acetone prior to

\footnotetext{
* THE SILESIAN UNIVERSITY OF TECHNOLOGY, FACULTY OF MECHANICAL ENGINEERING, WELDING DEPARTMENT, 18A KONARSKIEGO STR., 44-100 GLIWICE, POLAND

** THE SILESIAN UNIVERSITY OF TECHNOLOGY, FACULTY OF MECHANICAL ENGINEERING, INSTITUTE OF ENGINEERING MATERIALS AND BIOMATERIALS, 18A KONARSKIEGO STR, 44-100 GLIWICE, POLAND

*** THE SILESIAN UNIVERSITY OF TECHNOLOGY, FACULTY OF MECHANICAL ENGINEERING, DEPARTMENT OF FOUNDRY ENGINEERING, 18A KONARSKIEGO STR., 44-100 GLIWICE, POLAND

\# Corresponding author: damian.janicki@polsl.pl
} 
the LSA process. The alloying materials used were both a pure WC powder and a powder mixture of $\mathrm{WC}$ and titanium at the weight ratio of 1:0.1. The particle size range of $\mathrm{WC}$ and Ti powders was 200-300 $\mu \mathrm{m}$ and 40-70 $\mu \mathrm{m}$, respectively.

TABLE 1

Chemical composition of armor steel ARMOX 500T (wt. \%)

\begin{tabular}{|c|c|c|c|c|c|c|c|c|c|}
\hline \hline $\mathrm{C}$ & $\mathrm{Mn}$ & $\mathrm{Si}$ & $\mathrm{Mo}$ & $\mathrm{Cr}$ & $\mathrm{Ni}$ & $\mathrm{B}$ & $\mathrm{S}$ & $\mathrm{P}$ & $\mathrm{Fe}$ \\
\hline 0.32 & 1.20 & 0.40 & 0.7 & 1.00 & 1.80 & 0.005 & 0.010 & 0.015 & bal. \\
\hline
\end{tabular}

The SALs were made by means of a $2 \mathrm{~kW}$ continuous wave high power direct diode laser (Rofin-Sinar DL020) using weaving technique. The rectangular laser beam spot of size $1.8 \times 6.8 \mathrm{~mm}$ was focused on the top surface of the SM and oscillated transversely to the direction of the alloying process (the short axis of the beam was set parallel to the direction of alloying process). The amplitude of weaving of the laser beam was held constant at $12 \mathrm{~mm}$. The weaving frequency of the laser beam was in the range of $0.2-2.0 \mathrm{~Hz}$. The alloying powders were being injected into the molten pool in an argon gas stream via an off-axis flat powder injection nozzle. Argon was used as the shielding gas. The shielding gas nozzle having a $20 \mathrm{~mm}$ inside diameter was set coaxially with the powder injection nozzle. To evaluate the effect of the heat input (HI) and the Ti addition on the morphology of the SALs and the width of the HAZ, weave beads (WBs) were fabricated at various laser power levels (in the range of $900 \mathrm{~W}$ to $1200 \mathrm{~W}$ ) and traverse speeds of the laser beam (in weaving trajectory) ranging from $16.7 \mathrm{~mm} / \mathrm{s}$ to $25.0 \mathrm{~mm} / \mathrm{s}$ (Table 2). Because of the large laser beam weaving amplitude, the $\mathrm{HI}$ in this study was defined as the ratio of the laser power over the traverse speed of the laser beam in the weaving trajectory. For convenience, the SALs produced without and with the addition of titanium have been labelled WRLs and WTLs, respectively. The powder feed rate was in the range of $8 \mathrm{~g} / \mathrm{min}$ to $12 \mathrm{~g} / \mathrm{min}$, depending on the traverse speed of the laser beam.

TABLE 2

Effect of processing conditions on the SAL thickness and its microstructural parameters (in the optimal range of processing conditions)

\begin{tabular}{|c|c|c|c|c|c|c|c|c|}
\hline $\begin{array}{c}\text { Processing } \\
\text { condition no.* }\end{array}$ & $\begin{array}{l}\text { Laser power } \\
\text { (W) }\end{array}$ & $\begin{array}{c}\text { Weaving } \\
\text { frequency } \\
(\mathbf{H z}) \\
\end{array}$ & $\begin{array}{c}\text { Traverse } \\
\text { speed ** } \\
(\mathbf{m m} / \mathbf{s})\end{array}$ & $\begin{array}{c}\text { Heat input } * * * * \\
(\mathrm{~J} / \mathbf{m m})\end{array}$ & $\begin{array}{c}\begin{array}{c}\text { Powder feed } \\
\text { rate } \\
(\mathrm{g} / \mathrm{min})\end{array} \\
\end{array}$ & $\begin{array}{c}\text { Thickness of } \\
\text { the SAL } \\
(\mu \mathrm{m})\end{array}$ & $\begin{array}{c}\text { Matrix mean } \\
\text { free path } \\
{[\mu \mathrm{m}]} \\
\end{array}$ & $\begin{array}{l}\text { WC fraction } \\
\text { (vol\%) }\end{array}$ \\
\hline W1 & 1100 & 0.50 & 16.7 & 66 & 8 & 300 & $25 \pm 12$ & 50 \\
\hline WT1 & 1100 & 0.50 & 16.7 & 66 & 8 & 440 & $17 \pm 8$ & 59 \\
\hline WT2 & 1100 & 0.75 & 20.0 & 55 & 12 & 400 & $19 \pm 10$ & 63 \\
\hline WT3 & 1200 & 1.00 & 25.0 & 48 & 16 & 650 & $20 \pm 9$ & 71 \\
\hline
\end{tabular}

Remarks: *W and WT stand for the WRL and WTL; **traverse speed of the laser beam in the weaving trajectory; $* * *$ defined as the laser power divided by the traverse speed of the laser beam in the weaving trajectory

The microstructure of the SALs was studied using optical and scanning electron microscopy (SEM) with energy dispersive spectroscopy (EDS). Measurements of the volume fraction of embedded WC particles and the matrix mean free path between embedded WC particles (MFP) were performed using a Nikon NIS-Elements quantitative image analysis system. The X-ray diffraction measurements carried out in the present study were done by means of PANalytical X'Pert PRO MPD X-ray diffractometer equipped with a Co- $\mathrm{K}_{\alpha}(\lambda=1.79 \AA$ Á) source and an $\mathrm{X}^{\prime}$ Celerator detector. The X-ray tube was operated at $40 \mathrm{kV}$ and $30 \mathrm{~mA}$. Additionally, to provide deeper understanding of the microstructure evolution of the alloy matrix of the SALs, the thermodynamics calculations on Fe-C-W and Fe-C-W-Ti alloy systems were performed using the commercial Thermoc-Calc software. The Scheil module, based on the Scheil-Gulliver solidification model, which assumes an infinitely rapid diffusion in the liquid phase, no diffusion in the solid phase, local equilibrium at the solid/liquid interface and no FCC to BCC transformations, was used to predict the non-equilibrium solidification paths of the investigated alloy systems.

Microhardness testing was performed with a Wilson Wolpert 401 MVD Vickers hardness tester. The measurements were taken, with $200 \mathrm{~g}$ load for a dwell time of $5 \mathrm{~s}$, on the cross-section of the SALs in a straight line both perpendicular to the fusion boundary (FB) to cover the alloyed layer, HAZ and part of the SM and also parallel to the FB at the mid-thickness of the SAL.

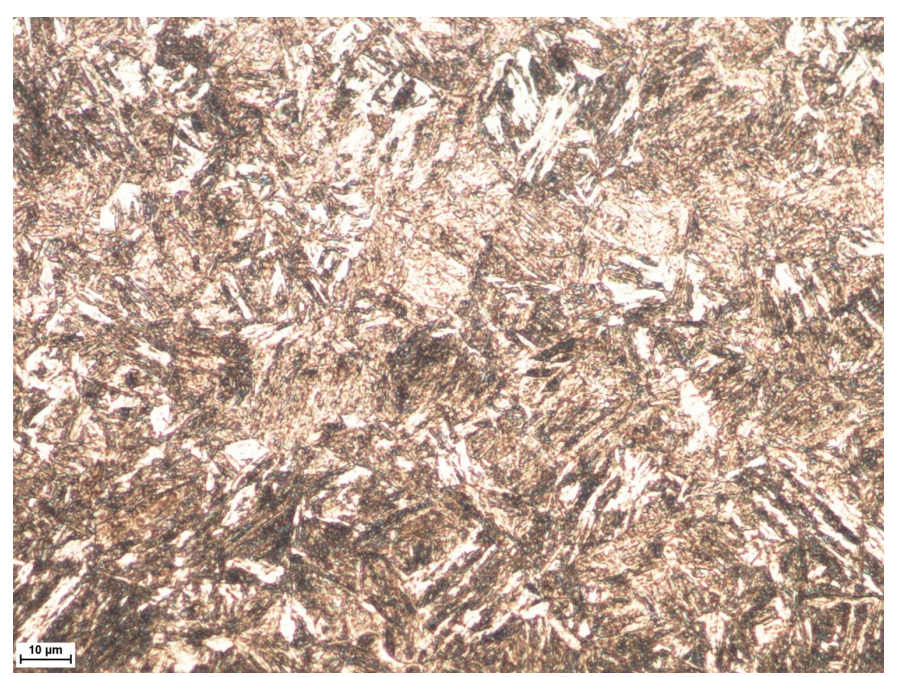

Fig. 1. Microstructure of the substrate material (ARMOX 500T) 


\section{Results and discussion}

Longitudinal macrographs of the WBs produced at different processing conditions (in the optimal range of processing parameters, TABLE 2) are presented in Fig. 2. A summary of measurements of a thickness of the SALs, the volume fraction of the embedded WC particles and the MFP is given in Table 2. Generally, the addition of a titanium powder during the investigated LSA process has a significant effect on both the thickness uniformity of SALs and also the WC fraction and the microstructure of the alloy matrix. The maximum thickness of the uniform SAL produced without and with addition of Ti was $300 \mu \mathrm{m}$ and $650 \mu \mathrm{m}$, respectively. Additionally, the WTLs have a higher WC volume fraction and a lower MFP in comparison to the WRLs. Quantitative analysis of micrographs of the SALs produced at the same HI level of $66 \mathrm{~J} / \mathrm{mm}$, without and with the Ti addition, indicated that the WC particles occupy about 50 vol\% and 59 vol $\%$, respectively. This suggests that the Ti addition increased the wettability of WC particles by the liquid metal in the molten pool. In turn, a higher amount of WC particles in the molten pool leads to a higher fusion depth, what provides the higher thickness of the SALs at the given HI level. This phenomenon can be explained by a higher absorption coefficient of tungsten carbide compared to the liquid steel absorption coefficient. The thickness of the above-mentioned SALs was $300 \mu \mathrm{m}$ and 450 $\mu \mathrm{m}$, respectively. Moreover, it is noteworthy that the higher wettability of WC enables to produce the SALs at higher traverse speeds of the laser beam, reducing the HI level and limiting the width of the HAZ. The minimum HI level, providing the SAL with the uniform thickness, was $66 \mathrm{~J} / \mathrm{mm}$ and $48 \mathrm{~J} / \mathrm{mm}$ for the WRL and the WTL, respectively. Note that the resulting WTL has the WC volume fraction of $71 \%$ and a thickness of $650 \mu \mathrm{m}$.

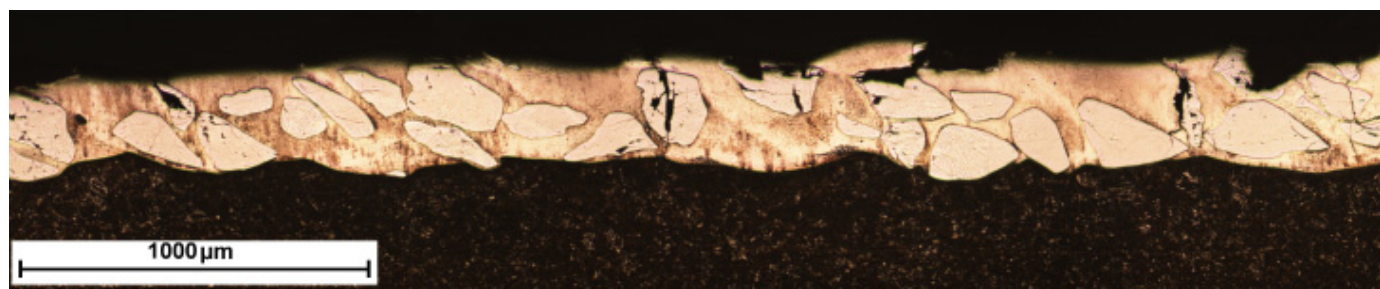

a)

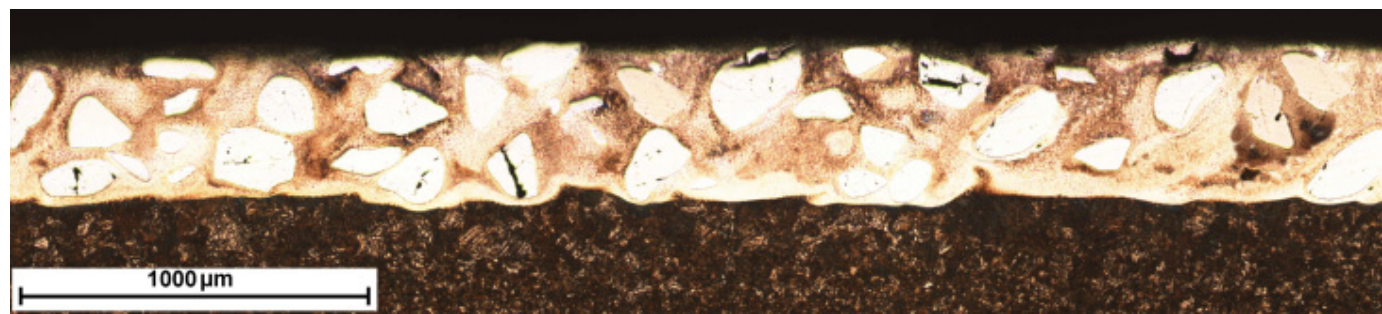

b)

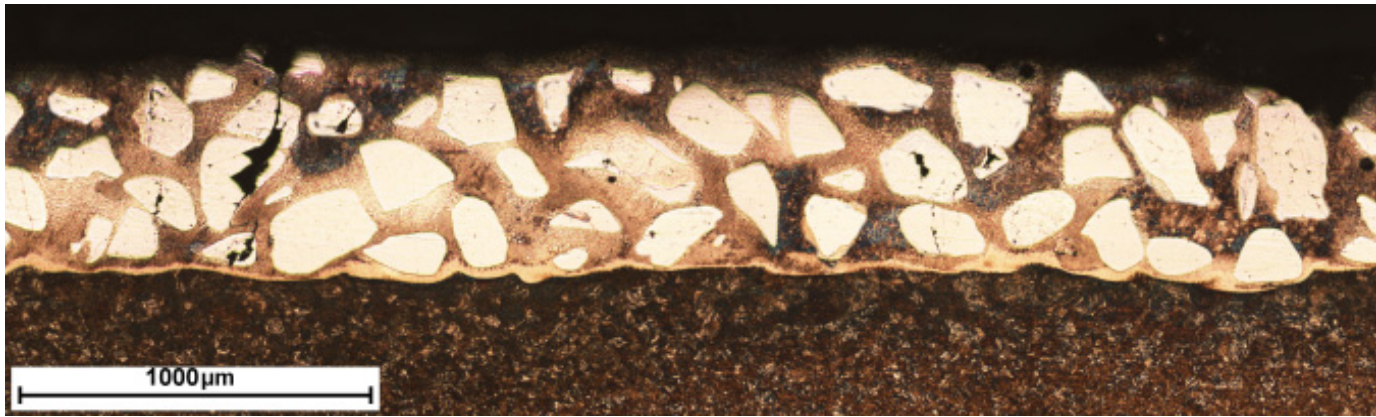

c)

Fig. 2. Longitudinal macrographs of the WBs produced under processing conditions no: a) W1; b) WT1; c) WT3, Table 2

SEM micrographs of the SALs produced at the HI of $66 \mathrm{~J} / \mathrm{mm}$ without and with the addition of titanium (condition no. W1 and WT1, TABLE 2) are shown in Fig. 3a and 3b, respectively. Higher magnification SEM images showing microstructures of the alloy matrix in the above SALs are presented in Fig. $4 \mathrm{a}$ and $3 \mathrm{~b}$, respectively. Typical XRD patterns for these SALs are depicted in Fig. 5. Generally, the microstructure of alloy matrix of the SALs produced without the Ti addition consists of austenite dendrites transformed to martensite and $\mathrm{W}$-rich phases, that are a result of a considerable enrichment of the molten pool in $\mathrm{W}$ and $\mathrm{C}$ by partial dissolution of the embedded WC particles. Based on energy-dispersive X-ray spectroscopy (EDS) analysis, the mean concentration of $\mathrm{W}$ in this alloy matrix (condition no. W1, Table 2) was estimated to be $25 \mathrm{wt} \%$. The $\mathrm{W}$-rich phases show both blocky and fishbone-like morphologies, depending on $\mathrm{W}$ and $\mathrm{C}$ concentrations. In the regions near the embedded $\mathrm{WC}$ particle, namely in regions with higher $\mathrm{W}$ and $\mathrm{C}$ contents, the W-rich phases exhibit a blocky morphology with the grain size 
up to $5 \mu \mathrm{m}$. In the case of regions with lower $\mathrm{W}$ and $\mathrm{C}$ contents, the W-rich phases have a fishbone-like structure. It should be noted that the fishbone-like W-rich phases are distributed in the interdendritic regions, whereas blocky phases are observed both in the dendritic and interdendritic regions. This clearly indicates that the solidification sequence of the alloy matrix is affected by the $\mathrm{W}$ and $\mathrm{C}$ contents. For the simulation of phase evolution during the solidification of the Fe-W-C alloy system under different compositions, the Scheil type of calculation was carried out. Fig. 6 presents the solidification paths for two Fe$\mathrm{W}-\mathrm{C}$ alloy compositions, namely Fe-20wt $\% \mathrm{~W}-1.25 \mathrm{wt} \% \mathrm{C}$ and Fe-30wt $\% \mathrm{~W}-2 \mathrm{wt} \% \mathrm{C}$, which represent the above-mentioned two morphologies of the alloy matrix: the region further away from the embedded WC particle and the region near the WC particle, respectively. The simulation results for the $\mathrm{Fe}-20 \mathrm{wt} \% \mathrm{~W}$ $1.25 \mathrm{wt} \% \mathrm{C}$ alloy system indicate that the first and the second phases to precipitate from the liquid alloy matrix are the primary austenite and $\mathrm{W}$-rich $\mathrm{M}_{6} \mathrm{C}$ complex carbide, respectively, Fig. 6b. Whereas, in the case of the alloy matrix with higher $\mathrm{W}$ and $\mathrm{C}$ contents, this solidification sequence is reversed, Fig. 6 a. Generally, in both alloy matrix compositions, the latter stages of solidification are the same, that is, the precipitation of the WC phase and cementite was predicted. The EDS spot analysis of the blocky phases revealed a high $\mathrm{W}$ and $\mathrm{Fe}$ content, suggesting that they are complex carbides $\left(\mathrm{M}_{6} \mathrm{C}\right) \mathrm{Fe}_{3} \mathrm{~W}_{3} \mathrm{C}$. XRD analysis of the WRL confirmed the presence of $\mathrm{Fe}_{3} \mathrm{~W}_{3} \mathrm{C}$ phase. Additionally, Xray diffraction data revealed the $\alpha \mathrm{Fe}$ (martensite), $\mathrm{WC}, \mathrm{W}_{2} \mathrm{C}$ and also a significant fraction of a complex carbide $\left(\mathrm{M}_{12} \mathrm{C}\right) \mathrm{Fe}_{6} \mathrm{~W}_{6} \mathrm{C}$. The presence of $\left(\mathrm{M}_{12} \mathrm{C}\right) \mathrm{Fe}_{6} \mathrm{~W}_{6} \mathrm{C}$ carbide is considered to be the result of decomposition of $\left(\mathrm{M}_{6} \mathrm{C}\right) \mathrm{Fe}_{3} \mathrm{~W}_{3} \mathrm{C}$. Published data involving the $\mathrm{Fe}-\mathrm{W}-\mathrm{C}$ alloy system indicates that the $\mathrm{Fe}_{6} \mathrm{~W}_{6} \mathrm{C}$

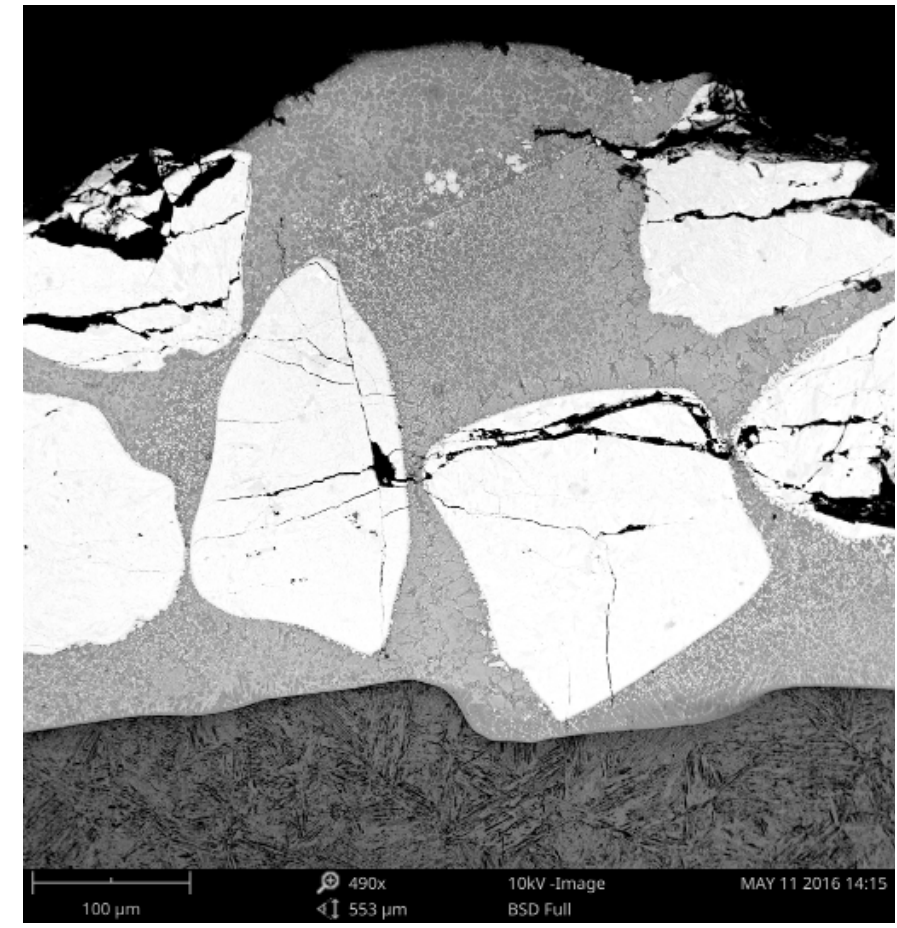

a) carbide is usually observed as a secondary carbide after the dissolution or decomposition of primary $\mathrm{Fe}_{3} \mathrm{~W}_{3} \mathrm{C}$ carbide [16]. It is also supported by thermodynamic calculations, that do not show the presence of $\mathrm{M}_{12} \mathrm{C}$ phase, under both non-equilibrium and equilibrium conditions, Fig. 6 and 7. Note that the used weaving technique produced the WBs that are, in general, consisted of overlapping stringer beads (approx. $1.5 \mathrm{~mm}$ width) with varied but relatively high overlapping ratios. This implies that the alloy matrix of SALs, after solidification, underwent several heating-cooling thermal cycles. Taking the above into account, it is reasonable to consider that during fabrication of these SALs the primary $\mathrm{M}_{6} \mathrm{C}$ decomposes into the $\mathrm{M}_{12} \mathrm{C}$ compound, which is significantly more thermodynamically stable [17]. The average microhardness of W-rich blocky phases was found to be $900 \mathrm{HV} \pm 150 \mathrm{HV}$. The volume fraction of all W-rich phases in the alloy matrix of the WRL (processing condition no W1, Table 2) is about $24 \%$. A uniform distribution of all Wrich phases throughout the matrix in this WRL and also their significant volume fractions result in high hardness values of alloy matrix up to $700 \mathrm{HV}$. The average hardness of this WRL was estimated to be $900 \mathrm{HV}$, Fig. 8. However, as can be seen in Fig. 3a, a relatively high hardness of this alloy matrix caused formation of crack network (also through WC particles), what in turn lead to loss of structural integrity of the SAL.

As can be seen from Fig 4b, the addition of Ti powder during the investigated LSA process considerably change the microstructure of the alloy matrix. In general, a strong carbide forming tendency of titanium resulted in the precipitation of TiC phase, what significantly reduced the fraction of W-rich complex carbides. The above-mention microstructural evolution in the SALs is directly caused by the change in the solidification

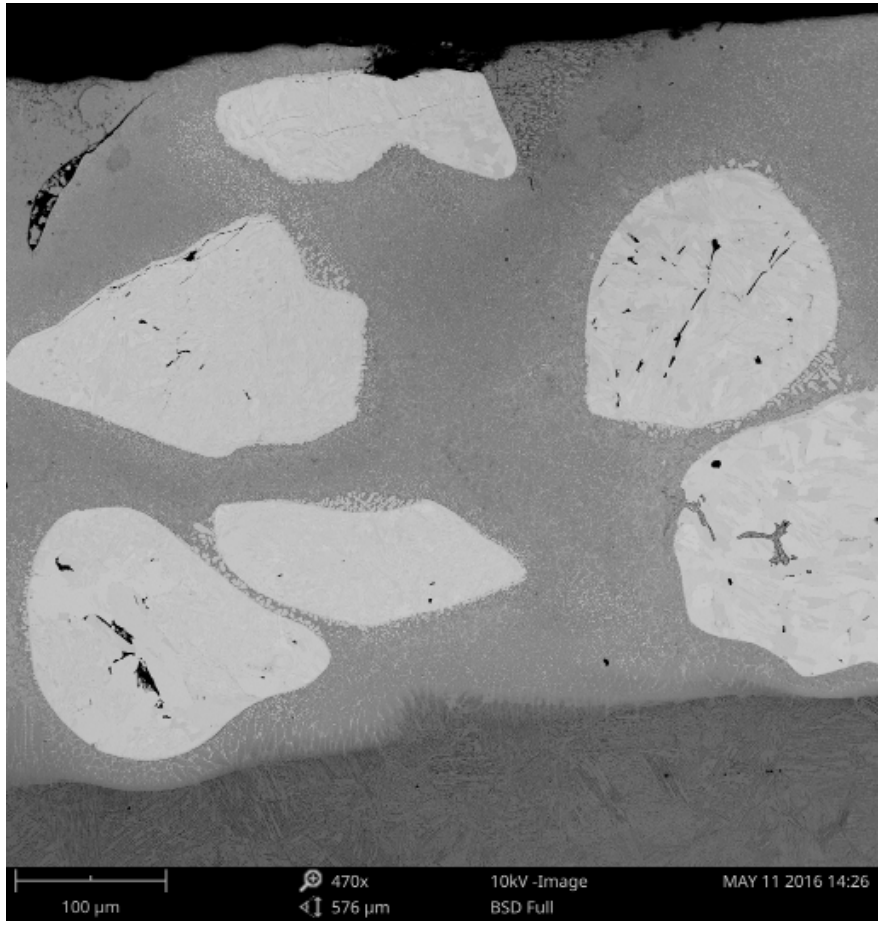

b)

Fig. 3. SEM micrographs of the SALs produced under processing conditions no: a) W1; b) WT1, Table 2 


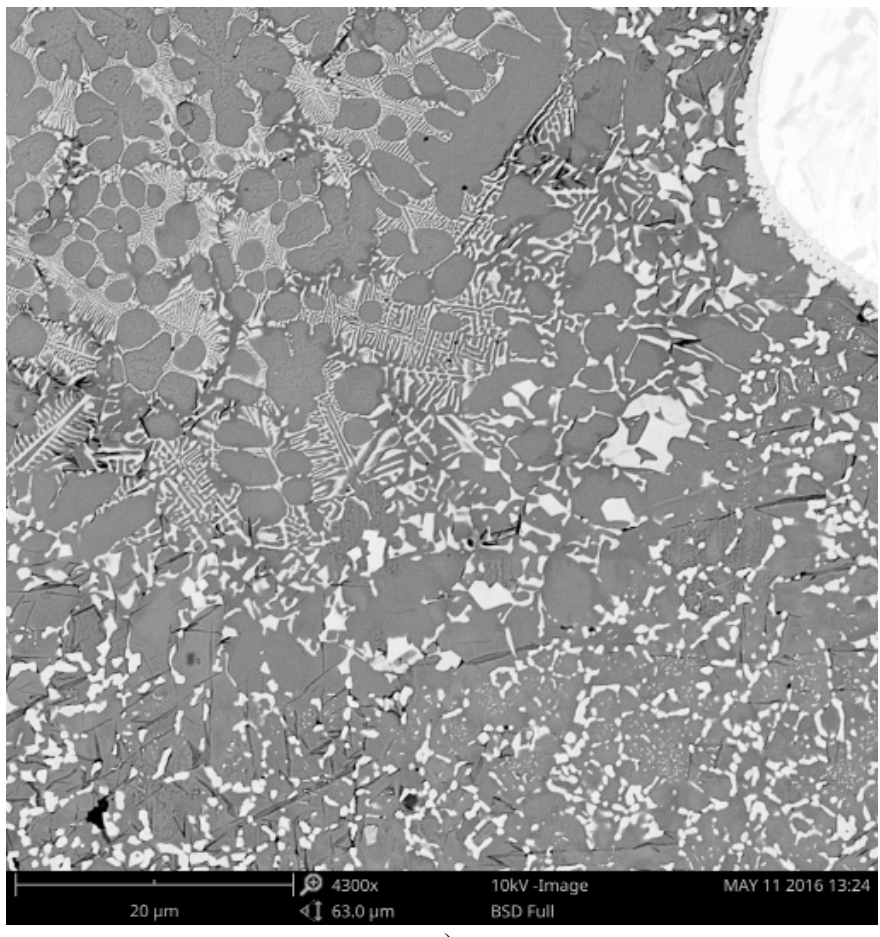

a)

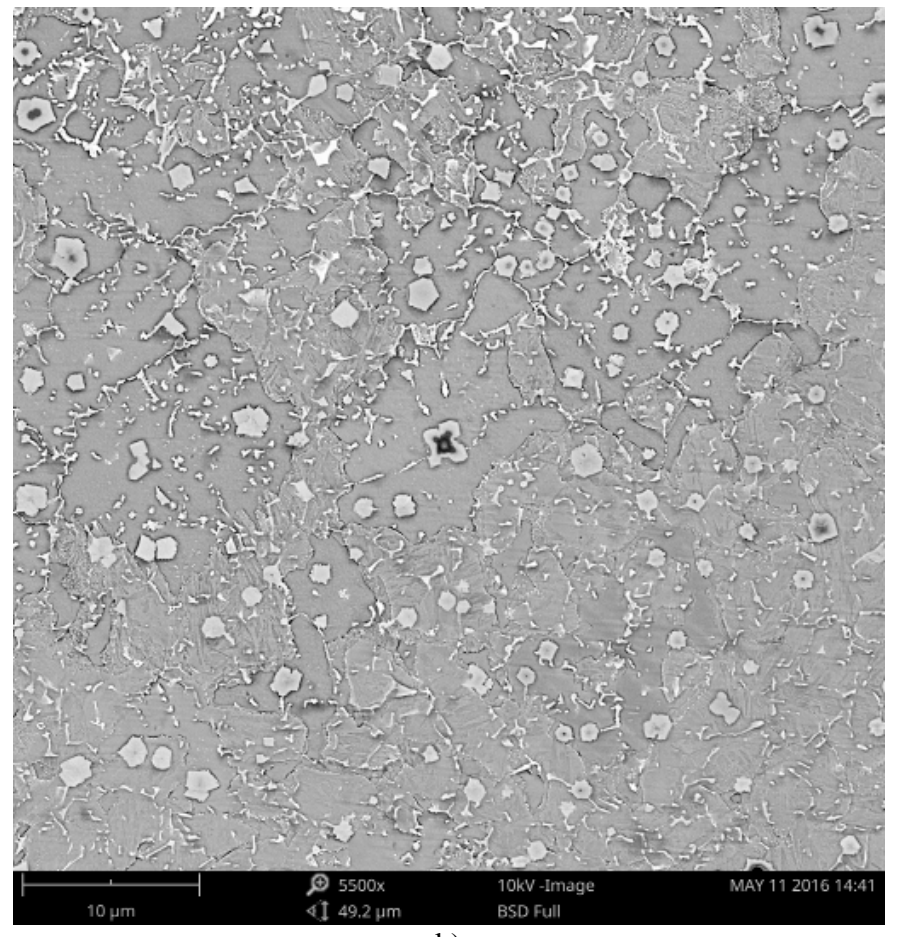

b)

Fig. 4. Higher magnification SEM images of the microstructure of the alloy matrix in the SALs produced under processing conditions no: a) W1; b) WT1, Table 2

a)

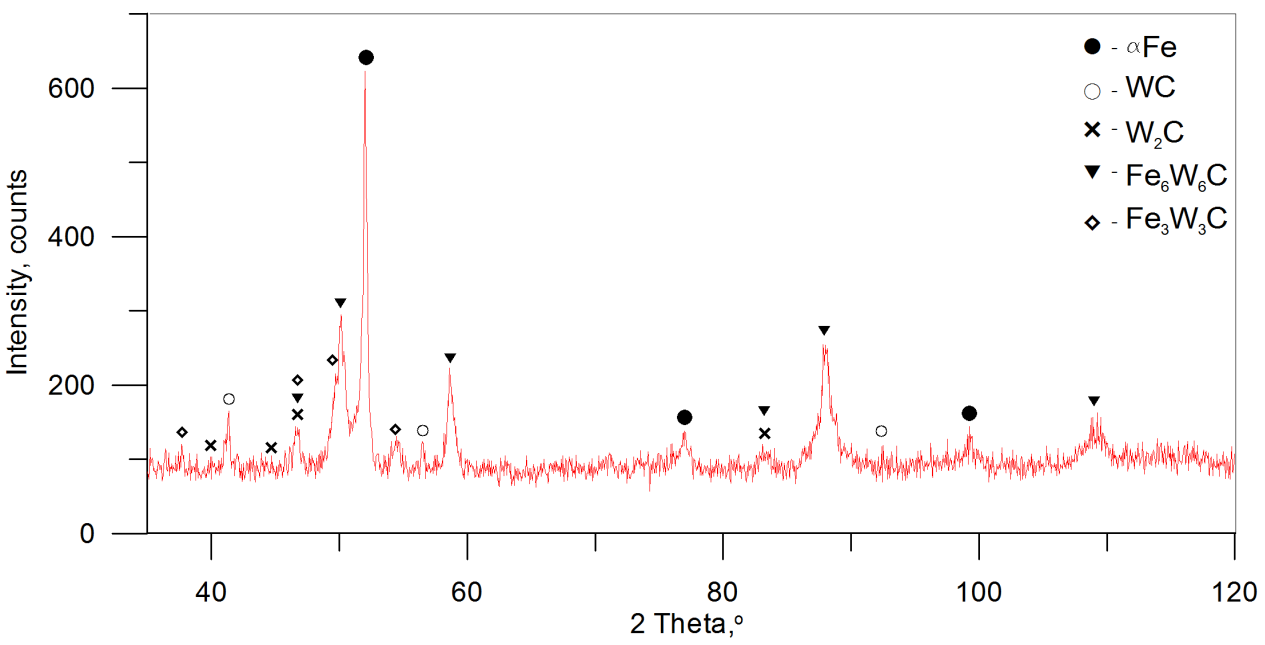

b)

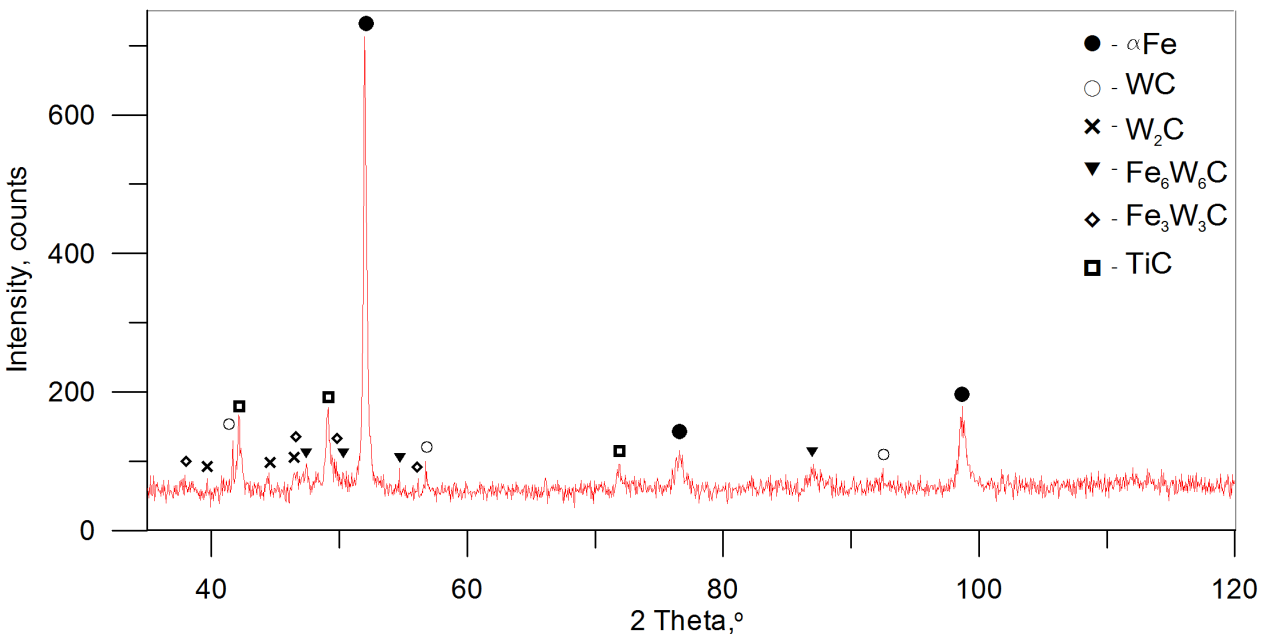

Fig. 5. XRD patterns of the SALs produced under processing conditions no: a) W1; b) WT1, Table 2 


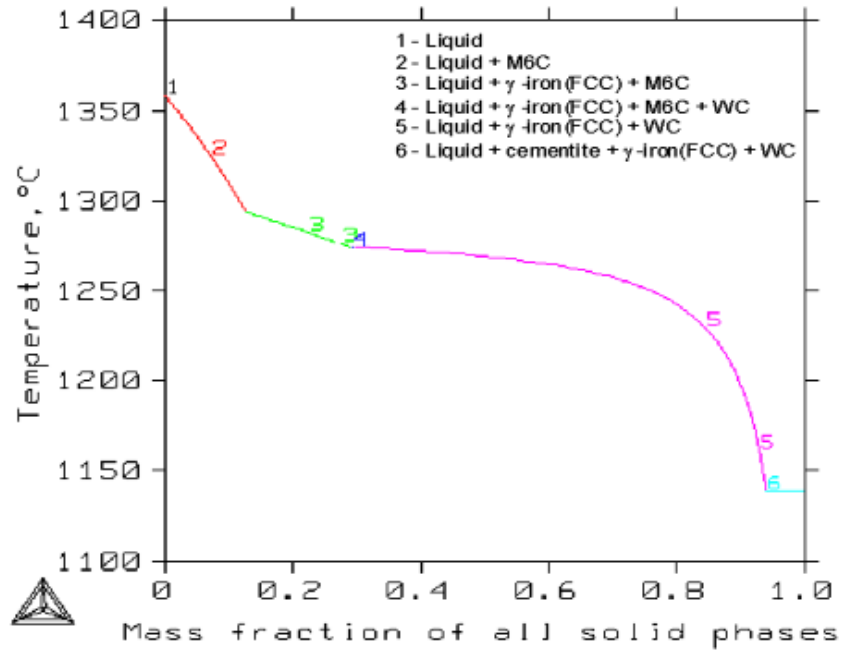

a)

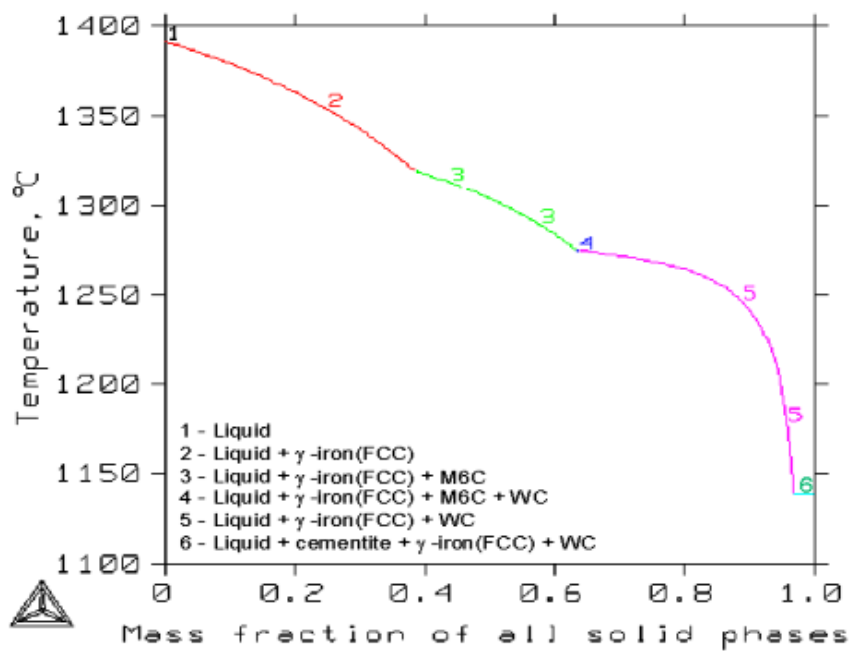

b)

Fig. 6. Evolution of fraction solid versus temperature for solidification of the Fe-W-C alloy system at different composition calculated under Scheil conditions: a) Fe-30wt $\% \mathrm{~W}-2 \mathrm{wt} \% \mathrm{C}$, a) Fe-20wt $\% \mathrm{~W}-1.25 \mathrm{wt} \% \mathrm{C}$

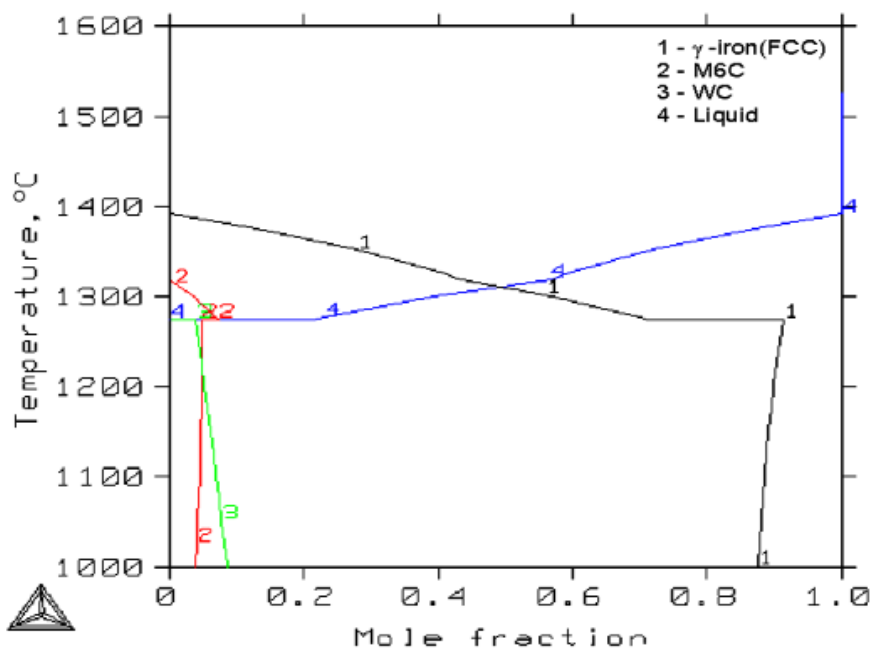

Fig. 7. Phase fraction versus temperature curves for $\mathrm{Fe}-20 \mathrm{wt} \% \mathrm{~W}-$ $1.25 \mathrm{wt} \% \mathrm{C}$ alloy system calculated under equilibrium condition

path of the alloy matrix, as a consequence of significant differences between the thermal stability of TiC and W-rich phases. Additionally, it should be noticed that the SALs produced with the Ti addition exhibit a markedly higher $\mathrm{W}$ content in the alloy matrix in comparison to that produced using pure $\mathrm{WC}$, at the same HI level and powder feeding rate. This is attributed mainly to a higher total volume fraction of the embedded WC particles. Moreover, as mentioned earlier, the higher fraction of WC particles in the molten pool can increase the absorption of laser energy and simultaneously the molten pool temperature. As a consequence, a more intensive dissolution of WC particles in the molten pool can occur. Based on EDS analysis, the mean concentrations of Ti, and $\mathrm{W}$ in the matrix alloy of the WTL produced under condition no WT1 (TABLE 2) were estimated to be $4 \mathrm{wt} \%$ and $35 \mathrm{wt} \%$, respectively. Thus, it is reasonable to assume that the above alloy matrix has also higher $\mathrm{C}$ content than that in the WRL produced under condition no. W1. The thermodynamic

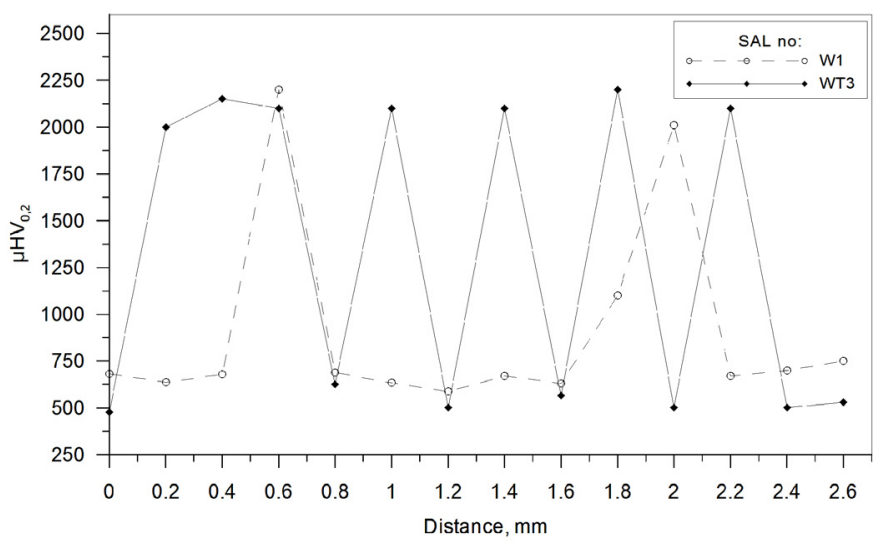

Fig. 8. Microhardness profiles on the cross section of the SALs produced under condition no W1 and WT3, Table 2. Profiles taken at mid depth of the SAL along line parallel to the FB

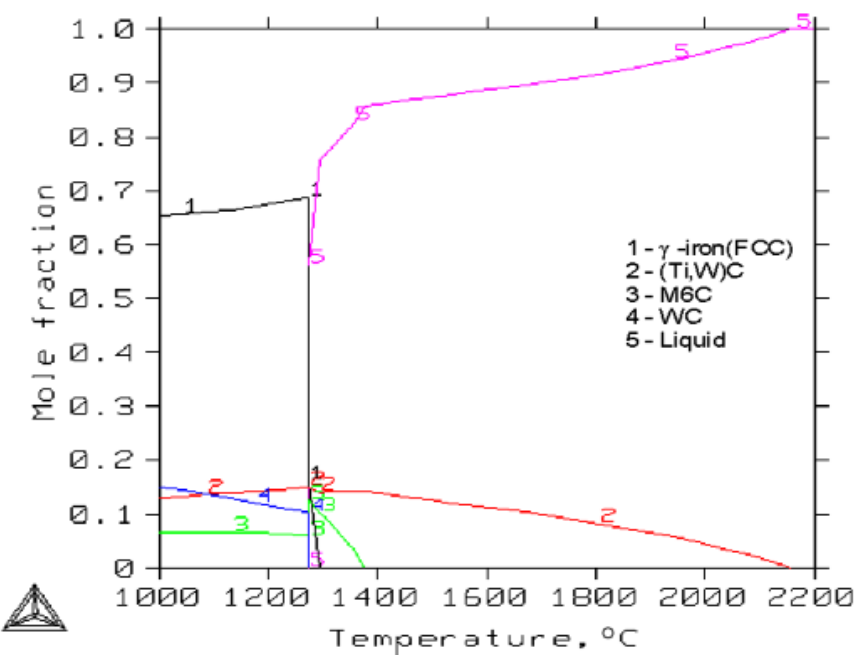

Fig. 9. Thermal stability of the phases in Fe-3wt $\% \mathrm{C}-4 \mathrm{wt} \% \mathrm{Ti}-35 \mathrm{wt} \% \mathrm{~W}$ alloy system 
calculations on the $\mathrm{Fe}-3 \mathrm{wt} \% \mathrm{C}-4 \mathrm{wt} \% \mathrm{Ti}-35 \mathrm{wt} \% \mathrm{~W}$ quaternary alloy system indicated that the $\mathrm{W}$-rich $\mathrm{M}_{6} \mathrm{C}$ complex carbide is thermally stable only up to about $1280^{\circ} \mathrm{C}$, whereas the $\mathrm{TiC}$, more precisely $(\mathrm{Ti}, \mathrm{W}) \mathrm{C}$ phase, persists up to $2150^{\circ} \mathrm{C}$, Fig. 9. The calculated solidification sequence of this alloy matrix predicted the solidification process starts with the formation of the $(\mathrm{Ti}, \mathrm{W})$ $\mathrm{C}$ phase. With continued cooling, the solidification occurs by the formation of $\mathrm{W}$-rich $\mathrm{M}_{6} \mathrm{C}$ complex carbide and austenite phase. The above-mentioned changes in the microstructure of the WRLs relative to the WTLs can also be clearly observed comparing their diffraction patterns, presented in Fig. 5. XRD analysis confirmed that the dominant phases in the alloy matrix of the WTLs are the $\alpha$-Fe phase and TiC phase. Additionally, the presence of complex carbide $\left(\mathrm{M}_{12} \mathrm{C}\right) \mathrm{Fe}_{6} \mathrm{~W}_{6} \mathrm{C}$ was detected as in the case of the WRLs.

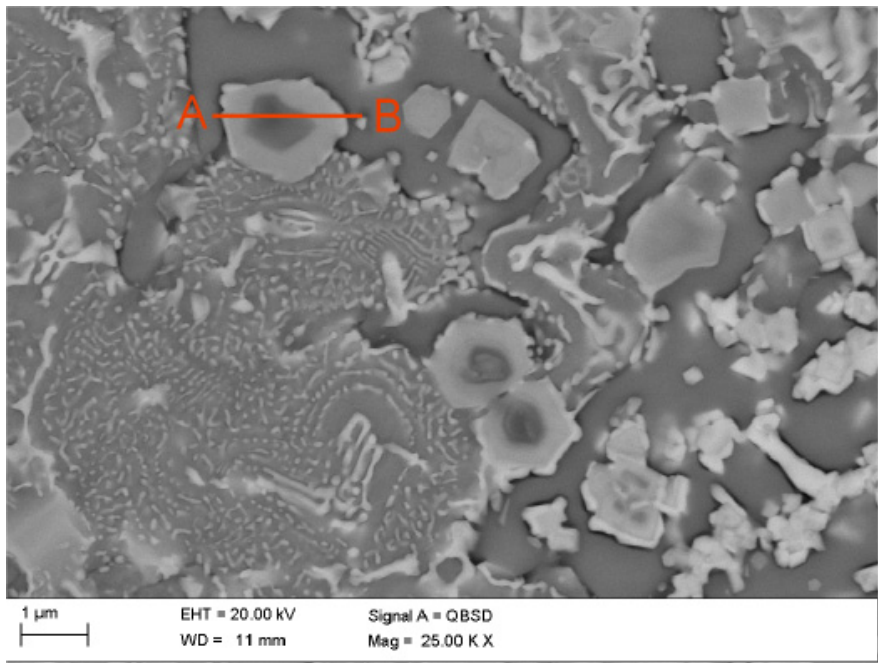

a)
The thermodynamic calculations of the $\mathrm{Fe}-3 \mathrm{wt} \% \mathrm{C}-4 \mathrm{wt} \% \mathrm{Ti}-$ $35 \mathrm{wt} \% \mathrm{~W}$ system indicate that under equilibrium condition the $(\mathrm{Ti}, \mathrm{W}) \mathrm{C}$ carbide will contain up to $30 \mathrm{wt} \%$ of W. Whereas, the $\mathrm{W}$ content in that phase, measured using EDS at the spot location in the center of the $(\mathrm{Ti}, \mathrm{W}) \mathrm{C}$ particles, was estimated to be approx. $40 \mathrm{wt} \%$. Furthermore, the back-scattered electron (BSE) image of the microstructure of alloy matrix in the WTL suggests the Ti concentration gradient within the (Ti,W)C particles, Fig. 10a. EDS line-scan analysis collected across the $(\mathrm{Ti}, \mathrm{W}) \mathrm{C}$ particle clearly showed the highest $\mathrm{Ti}$ content at the center of this particle, Fig. 10b. Additionally, the above BSE image revealed that the $(\mathrm{Ti}, \mathrm{W}) \mathrm{C}$ phase acts as a nucleation site for the precipitation of $\mathrm{W}$-rich carbides. The $(\mathrm{Ti}, \mathrm{W}) \mathrm{C}$ particles are uniformly distributed throughout the alloy matrix and, in the case of the WTL produced under condition no WT1 (Table 2), their volume fraction reached

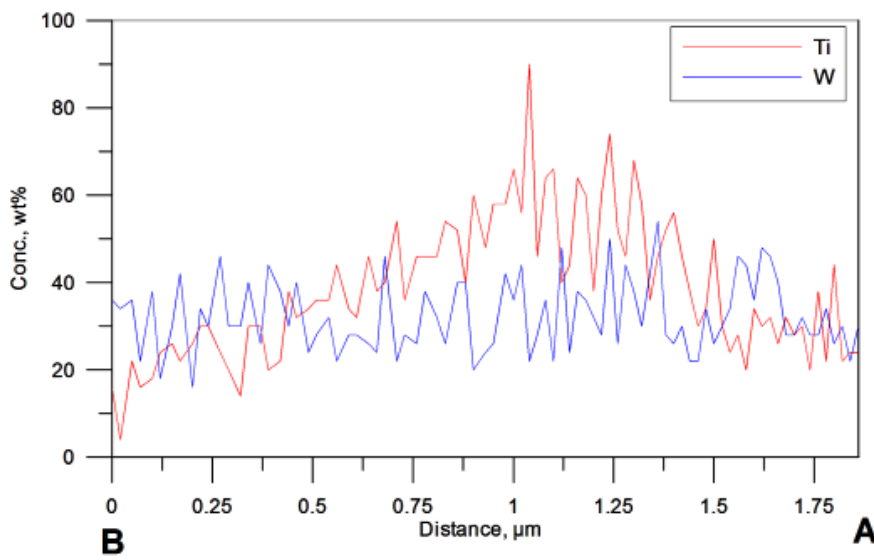

b)

Fig. 10. a) representative BSE image showing the alloy matrix of the WTL produced under processing condition no WT3 (Table 2) and b) EDS line-scan analysis across the (Ti,W)C phase (profile taken along the line marked in Fig. 10a)

approx. $8 \%$. An average particle size of the $(\mathrm{Ti}, \mathrm{W}) \mathrm{C}$ particles is about $2 \mu \mathrm{m}$. It should be pointed out that the formation of $(\mathrm{Ti}, \mathrm{W})$ $\mathrm{C}$ phase considerably reduced the fraction of the W-rich complex $\mathrm{M}_{6} \mathrm{C}$ and $\mathrm{M}_{12} \mathrm{C}$ carbides. The volume fraction of W-rich carbides in the above alloy matrix was estimated to be approx. $6 \%$. This, in turn decreased the cracking tendency of the WTLs and improved their structural integrity, simultaneously ensuring a high hardness of the alloy matrix. The average hardness of the alloy matrix in the WTL produced under condition no WT3 (Table 2) was $500 \mathrm{HV}$. The high fraction of the embedded WC in this WRL and the low MFP provide the total hardness value of $1300 \mathrm{HV}$.

An important issue to consider during the investigated LSA process of ARMOX 500T steel plates is the effect of thermal cycle on phase transformations occurring in the HAZ, and in consequence on the hardness of this region. The microstructure at different locations in the HAZ of the SAL produced at the HI of $55 \mathrm{~J} / \mathrm{mm}$ is shown in Fig. 11. The microhardness distributions in the HAZ of the SAL produced at different $\mathrm{HI}$ levels are plotted in Fig. 12. Generally, the HAZ comprises of three subregions: coarse grained zone (CGHAZ) adjacent to the $\mathrm{FB}$, fine grained zone (FGHAZ) and the region close to the BM including sub-critical and inter-critical zones (SICHAZ), Fig 11. The microstructure of CGHAZ region contains martensite-austenite islands in large untempered lath martensite and results from the recrystallization, Fig. 11a. The hardness of this region is in the range of $500 \mathrm{HV}$ to $560 \mathrm{HV}$, depending upon the $\mathrm{HI}$ level. The FGHAZ, which exhibits predominantly very fine untempered martensite, Fig. 11b, has similar values of hardness. The total width of the above two zones was approx. $500 \mu \mathrm{m}$ and $250 \mu \mathrm{m}$ at the HI of $55 \mathrm{~J} / \mathrm{mm}$ and $66 \mathrm{~J} / \mathrm{mm}$, respectively. In the next part of the HAZ, namely in the SICHAZ, hardness decreases sharply to a minimum values and next gradually increases up to approx. $500 \mathrm{HV}$ in the SM. This reduction in hardness (softening) results from tempering of the martensite phase. The microstructure of SICHAZ, in the softest region, consists of a heavily tempered martensite, possibly with some bainite, Fig. 11c. Higher heat 


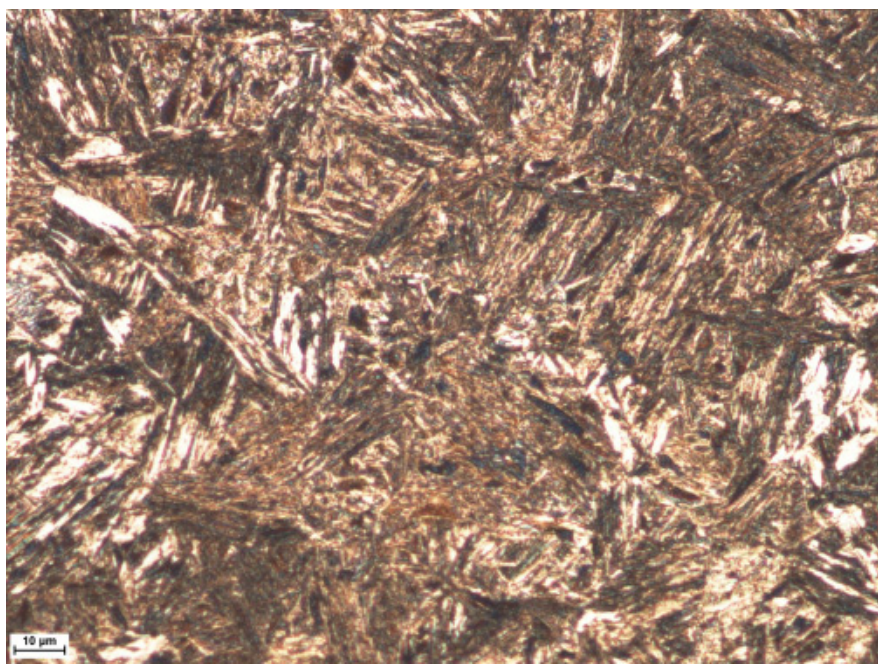

a)

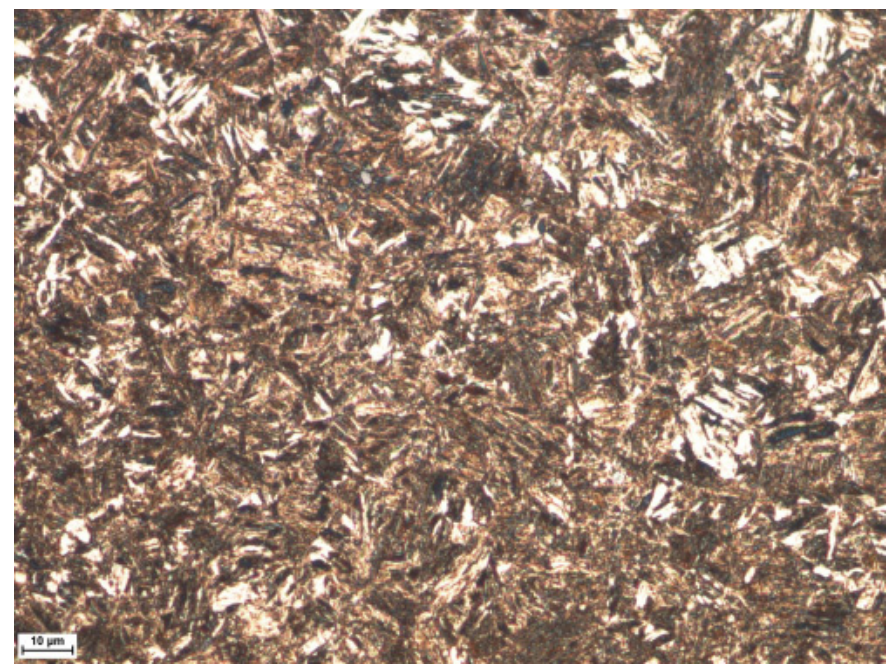

b)

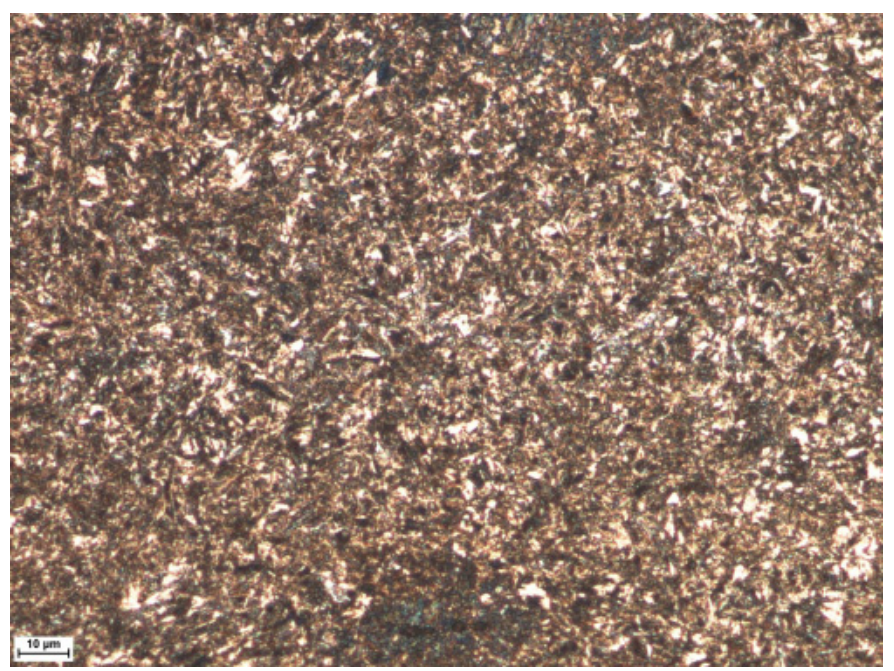

a)

Fig. 11. Optical micrographs of the HAZ in the SAL produced under processing parameters no WT3 (Table 2): a) CGHAZ; b) FGHAZ; c) SICHAZ

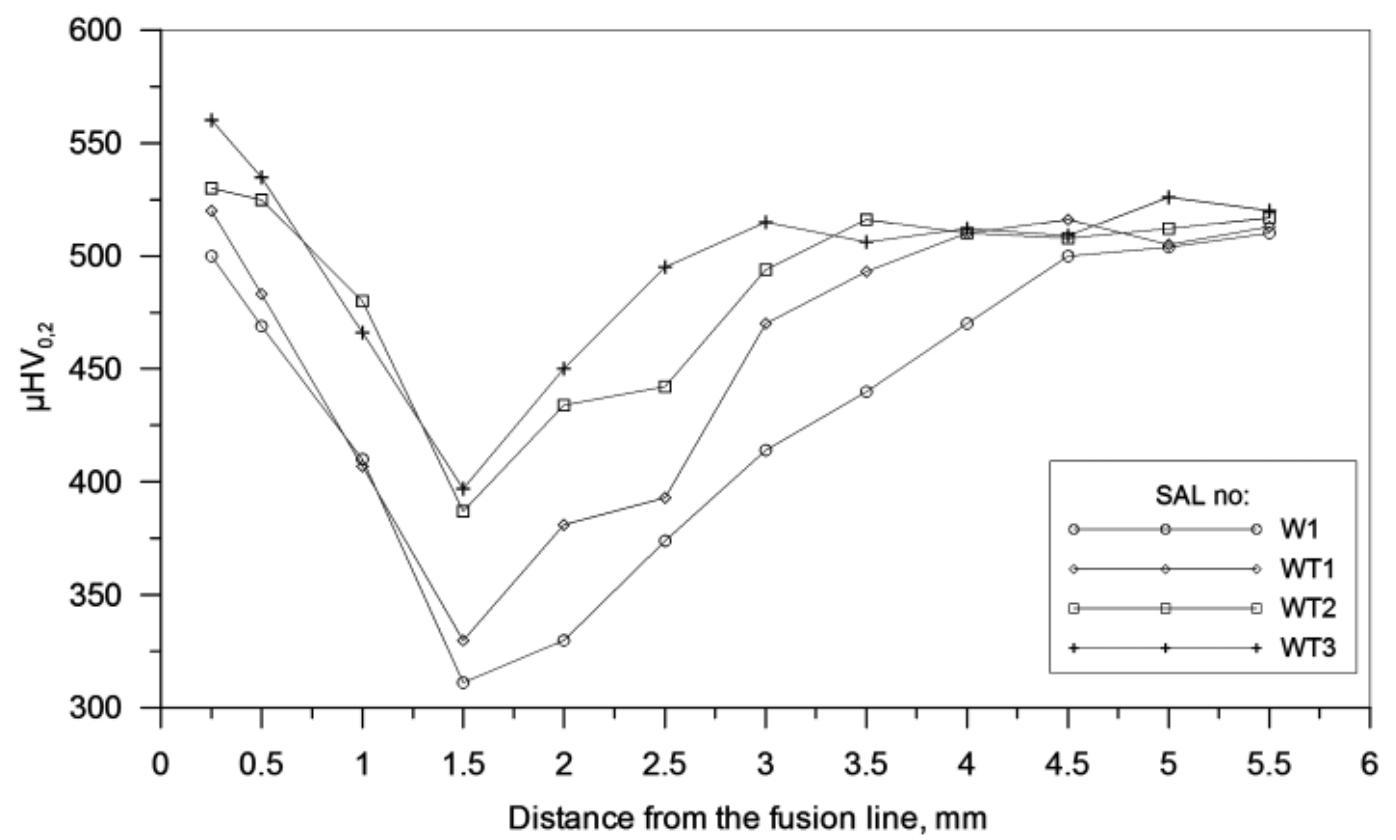

Fig. 12 Microhardness profiles in the HAZ of the SALs produced under different processing conditions (Table 2) 
inputs, causing longer thermal cycles and lower cooling rates, result in the higher degree of tempering, and in consequence lower values of hardness and the wider softened region. In the case of the highest HI level $(66 \mathrm{~J} / \mathrm{mm})$, the width of the softened region of the HAZ and the lowest hardness value were approx. $4.0 \mathrm{~mm}$ and $320 \mathrm{HV}$, respectively. However, the $\mathrm{HI}$ level of $48 \mathrm{~J} / \mathrm{mm}$, providing the uniform WTLs with a thickness of $650 \mu \mathrm{m}$ and an average hardness of $1500 \mathrm{HV}$ (processing condition no. WT3, Table 2), reduces the width of the softened region to about $2.0 \mathrm{~mm}$. Note that the lowest hardness values in this HAZ were found to be about $400 \mathrm{HV}$.

\section{Conclusion}

The present study has shown that the LSA process using a laser with the top-hat beam profile and a direct injection of the allowing powder into the molten pool enables the fabrication of WC-reinforced composite surface layers on the armor steel plate ARMOX 500T having a thickness of $650 \mu \mathrm{m}$ and an average hardness of $1300 \mathrm{HV}$, markedly limiting the loss of hardness in the HAZ (to $400 \mathrm{HV}$ ). The weaving technique and the addition of titanium powder allow to reduce the width of the softened region in the HAZ to approx. $2.0 \mathrm{~mm}$. The addition of titanium powder improved the wettability of WC particles by liquid metal in the molten pool, what resulted in both the higher SAL thickness and the higher WC fraction compared to the SALs produced using pure WC powder. Furthermore, the presence of titanium in the molten pool changed the solidification path of the alloy matrix. The resulting synthesis of $(\mathrm{Ti}, \mathrm{W}) \mathrm{C}$ phase, uniformly distributed in the alloy matrix between embedded WC particles, considerably reduced the volume fraction of the W-rich complex $\mathrm{M}_{6} \mathrm{C}$ and $\mathrm{M}_{12} \mathrm{C}$ carbides. This in turn decreased the cracking tendency of the SALs and improved their structural integrity.

\section{Acknowledgement}

Publication of this article was funded by statutory grant of Faculty of Mechanical Engineering, Silesian University of Technology.

\section{REFERENCES}

[1] M.K. Aghajanian, A.L. McCormick, A.L. Marshall, W.M. Waggoner, P.K. Karandikar, in: J.J. Swab (Ed.), Advances in Ceramic Armor VI, A John Wiley \& Sons, Inc., New Jersey 2010.

[2] H. Chang, J. Binner, R. Higginson, in: J.J. Swab (Ed.), Advances in Ceramic Armor VI, A John Wiley \& Sons, Inc., New Jersey 2010.

[3] M. Garcia-Avila, M. Portanova, A. Rabiei, Procedia Materials Science 4, 151-156 (2014).

[4] T. Borvik, S. Dey, A.H. Clausen, Int. J. of Impact Eng. 36, 948-964 (2009).

[5] I. Barényi, O. Híreš, P. Lip, Problems of Mechatronics Armament, Aviation, Safety Eng. 14, 7-14 (2013).

[6] D. Janicki, Arch. Metall. Mater. 59 (4), 1641-1646 (2014).

[7] K. Labisz, T. Tański, M. Kremzer, D. Janicki, Int. J. Mater. Res. 108 (2), 126-132 (2017).

[8] D. Wojnowski, Y.K. Oh, J.E. Indacochea, J. Manuf. Sci. Eng. 122 (2), 310-315 (2000).

[9] G. Madhusudhan Reddy, T. Mohandas, K.K. Papukutty, J. Mater. Process. Tech. 74, 27-35 (1998).

[10] L.A. Dobrzański, M. Czaja, W. Borek, K. Labisz, T. Tański, Int. J. Mater. Prod. Tec. 51 (3), 264-280 (2015).

[11] A. Klimpel, L.A. Dobrzański, A. Lisiecki, D. Janicki, J. Mater. Process. Tech. 164, 1046-1055 (2005).

[12] T. Liyanage, G. Fisher, A.P. Gerlich, Wear 274-275, 345-354 (2012).

[13] M. Musztyfaga-Staszuk, L.A. Dobrzański, Cent. Eur. J. Phys. 12 (12), 836-842 (2014).

[14] A. Lisiecki, Metals 5, 54-69 (2015).

[15] D. Janicki, M. Musztyfaga-Staszuk, Stroj. Vestn-J. Mech. E. 62 (6), 363-372 (2016).

[16] R. Ahmed, H. Yu, V. Stoica, L. Edwards, J.R. Sentisteban, Mat. Sci. Eng. A 498, 191-202 (2008).

[17] D.V. Suetin, I.R. Shein, A.L. Ivanovskii, Physica B 404 (20), 3544-3549 (2009). 